\title{
O A POSTERIORI TRANSFERENCIAL DOS TRAUMAS DO INÍCIO DA VIDA
}

Jacques André

Jacques André

Psicanalista,

professor da

Universidade

Denis Diderot

(França), diretor

do Centre d'Études

en Psychopatologie

et Psychanalyse

(Cepp) dessa

Universidade.

Membro efetivo

da Association

Psychanalytique de

France (APF).

Tradução de

Pedro Henrique

Bernardes Rondon

RESUMO: O a posteriori é uma das únicas noções psicanalíticas que permitem compreender os mecanismos da mudança psíquica. Muitas vezes confundida com uma simples significação de retrospectiva, trata-se, de fato, de noção complexa que envolve a concepção psicanalítica da temporalidade e a teoria do trauma. Em que medida o tratamento psicanalítico, a experiência da transferência, é capaz de pôr em jogo novamente os traumas do início da vida, de produzir sobre estes um efeito de a posteriori, e permitir mudança psíquica em relação às camadas mais primitivas do psiquismo?

Palavras-chave: A posteriori, trauma do início da vida, transferência, sexualidade infantil, ausência.

ABSTRACT: The transferential a posteriori of early traumas. The a posteriori is one of the few psychoanalytic concepts to allow understanding the mechanisms of psychic change. Often mistaken as a simple meaning hindsight, it is actually a complex concept that involves the psychoanalytic conception of temporality and the theory of trauma. To what extent is psychoanalysis, the experience of transference, able to bring early traumas into play, to produce a hindsight effect and to allow psychic change related to the most primitive layers of psyche?

Keywords: A posteriori, early trauma, transference, infantile sexuality, absence. 


\section{ALGUMAS OBSERVAÇÕES PRELIMINARES...}

O a posteriori é uma noção complexa e frágil, porque reúne duas dimensões heterogêneas cuja associação não é simples nem evidente:

- Sob seu aspecto mais familiar, o a posteriori evoca uma atribuição de sentido, uma significação, uma simbolização que intervém depois... que o acontecimento se produziu, num segundo tempo.

- Entretanto, a originalidade da noção é ter como solidários essa abertura do sentido e um momento traumático, um golpe.

O a posteriori é a reunião paradoxal de um trauma (que pressupõe um arrombamento [efração] das fronteiras do eu) e de um sentido que advém ou se transforma. É frequente que tenha resultado daí um esmaecimento da noção, e quando uma das duas noções se apaga, é sempre o trauma que é negligenciado. Não resta senão uma significação tardia, postergada em relação à ocasião do acontecimento. É evidente que não é necessária a psicanálise para pensar esse desencontro do acontecimento e do sentido, essa dimensão constitui o comum da reflexão do historiador.

O sucesso da tradução do termo freudiano nachträglich, Nachträglichkeit pelo termo francês après-coup [a posteriori] não se refere tanto a après, mas a coup [golpe], o que ressalta em especial a dimensão de violência traumática. A noção de trauma é pré-psicanalítica: a contribuição original de Freud a essa teoria do trauma foi precisamente ter definido o trauma psíquico como um golpe em dois tempos, o que o termo a posteriori quer dizer. São necessários dois golpes, dois traumas, para formar um trauma psíquico.

A noção de a posteriori tem grande importância prática. A mudança psíquica buscada pelo tratamento pressupõe reescrever a história, talvez mesmo uma primeira construção desta nas configurações borderline. É impossível contar apenas com a rememoração, só com a perlaboração, para que essa nova atribuição de sentido possa aparecer. Os golpes, isto é, os momentos traumáticos, são necessários. De que maneira o tratamento poderá produzir golpes, fazer com que advenham acontecimentos que tenham esse valor traumático e fecundo? A resposta a esta pergunta é inseparável das configurações clínicas singulares. No quadro geral das psiconeuroses, das neuroses de transferência, isto é, com os pacientes para os quais a psicanálise foi inventada, os golpes são previstos pelo método: pelo lado do paciente, o Einfall, a ideia incidente. E pelo lado do analista, o golpe trazido pela interpretação, dois microtraumas. A ideia incidente corresponde a um momento em que surge uma representação que, até então, não tinha tido verdadeiro acesso à consciência, o primeiro sinal de uma suspensão do recalcamento. Quanto à interpretação, é sempre uma violência, uma efração [arrombamento], mesmo que, com todo o tato, o analista tenha se esforçado para torná-la palatável. É claro que é preciso acrescentar a esses dois elementos a 
dimensão da transferência, seu caráter de repetição, de atuação do inconsciente. É este que dá à ideia incidente, como à interpretação, sua intensidade, a de estar in praesentia [estar presente], seu possível valor dinâmico.

Enquanto isso, é sabido que a dificuldade, a impossibilidade de simplesmente contar com os recursos do método começa desde as psiconeuroses, em particular com a neurose obsessiva. Foi para esta que Freud introduziu um golpe suplementar, quando fixou um termo para um tratamento que corria o risco de se tornar interminável, primeira medida de técnica ativa. Uma vez que faz do ritual psicanalítico um dos seus rituais-sintomas suplementares, uma vez que transforma a regressão transferencial num modo de satisfação, o neurótico obsessivo se instala em psicanálise como se estivesse em casa, paralisando os motores da mudança. Às voltas com as mesmas dificuldades de Freud, Lacan decide interromper a sessão antes da hora e virá a transformar esse ato contratransferencial em modalidade técnica sob o nome de escansão ou pontuação. Freud, tanto quanto Lacan, conta com esse golpe aplicado para voltar a engatar uma dinâmica paralisada.

Entretanto, a questão mais original, a mais interessante, se refere, é claro, aos pacientes para os quais a psicanálise não foi inventada e que constituem um desafio para o método. Para o paciente psiconeurótico, em particular o histérico — isto é, quanto àquele para o qual o inconsciente é quase idêntico ao recalcado - o fenômeno do a posteriori já fez seu trabalho. O objetivo do tratamento é o de reproduzir e não o de criar o movimento, para que, de a posteriori em a posteriori, o recalcamento seja suspenso. É essencial ter em mente que, para Freud, recalcamento e a posteriori são solidários. O recalque propriamente dito — o recalque secundário — é um recalque a posteriori. Então, a sequência é esta: um acontecimento potencialmente traumatico é registrado pelo psiquismo sem ser tratado, apenas impresso (por exemplo, a visão do coito dos pais pela criança muito pequena, futuro Homem dos Lobos, por ocasião de uma sesta). Mais tarde, talvez anos mais tarde, surge um segundo acontecimento que, por associação, desperta a marca antiga, lhe dá toda sua força traumática e provoca o recalcamento e suas consequências neuróticas (no caso do Homem dos Lobos criança, esse segundo acontecimento é o sonho de angústia, que engendra a neurose infantil).

O conluio entre recalcamento e a posteriori enfatiza que o recalcamento não é uma simples forma de afastar, de rejeitar, é também uma transformação, uma ressignificação. Para simplificar a oposição, digamos que, para os pacientes borderline, os primeiros golpes, os primeiros ataques, não são objeto desse tratamento psíquico que é o próprio recalcamento. Pode-se supor que esses primeiros impactos traumáticos, quer tenham ficado aí depositados, enquistados, enclavados, meaning-free [livres de significado] — portanto em estado de recalque originário —, 
quer tenham sofrido um primeiro tratamento tipo desmentido, clivagem, projeção, identificação com o agressor, etc., no mesmo ato a tarefa prática é que se encontra modificada: não se trata mais de buscar a suspensão ou a supressão do recalcamento, mas sim a "correção (ou a transformação) a posteriori do processo de recalcamento originário” (FREUD, 2010/1937, p.28). Como será que o tratamento psicanalítico pode esperar cumprir tal tarefa, com quais recursos, com quais forças? Será que isso pressupõe arranjos técnicos, modificação do método? Essa é a ideia principal deste artigo.

Que esperança de transformação a posteriori a psicanálise pode alimentar quando aquilo de que o paciente sofre está enraizado em traumas do início da vida? Só mesmo a pergunta é que é simples... Sem dúvida é preciso, em primeiro lugar, distinguir entre transformar e curar. Parece, ao mesmo tempo, mais familiar e menos misteriosa a dimensão terapêutica pela qual o tratamento psíquico trabalha para pensar a ferida, aplicar um curativo, fazê-la cicatrizar. Transformar é outra coisa, que pressupõe conseguir um sentido novo — talvez mesmo o nascimento do sentido propriamente dito.

“Traumas do início da vida”: esta expressão é carregada de obscuridade que não se deve apenas ao fato de que houve uma efração [arrombamento] muito cedo no tempo. Qual a natureza desses traumas? Não basta responder que são de natureza sexual; o vital e a destrutividade também fazem parte quer prevaleça tal ou qual sentido, ou mesmo que os três sentidos estejam intrincados.

A precocidade é também a do eu. “Trauma” em psicanálise é um termo relativo, todo trauma é do eu, inseparável das fronteiras que cruza ou pisoteia. O próprio Freud, em L’homme Moïse (2010/1937), encarregou-se de enfatizar a acentuação da componente narcísica no momento em que o eu é incapaz de integrar, de encerrar aquilo que lhe acontece. E depois há o outro, o ambiente humano, os Nebenmenschen [os humanos semelhantes], eles mesmos cindidos pela alteridade, pela alteridade do inconsciente. Toda inscrição, todo choque traumático cristaliza alguma coisa dessa situação inter-humana: para um trauma, é preciso ser dois. A situação transferencial, analítica, ela própria interpsíquica, encontra aí as condições de sua eventual eficácia reproduzindo algo da cena inaugural.

O trauma, em primeiro lugar, é uma noção econômica, uma quantidade. Entretanto, é impossível restringir-se a esse único aspecto, negligenciando a vertente da qualidade. Eis duas ilustrações, escolhidas nos extremos. De um lado, uma criança que está mamando e que, quando olha para o rosto de sua mãe, não vê nada, apenas um olhar que não o vê, perdido nas brumas da depressão. De outro lado, um bebê mamando numa mãe a quem o aleitamento conduz à beira da experiência orgástica, e em cujos olhos ele lê a excitação que está lhe proporcionando. Se o impacto traumático está garantido nesses dois casos — pelo menos é possível supor que sim — como é que o fato de ser atingido pelo nada 
ou pelo demais poderia depositar o mesmo tipo de marcas, e convocar o mesmo tipo de elaboração?

Que esperança de a posteriori pode haver então? O trauma do início da vida é divisível por dois? O acontecimento pode surpreender o retorno do mesmo? Será possível passar-se da litania à história? Será que a dinâmica do a posteriori pode erradicar a compulsão à repetição? Estamos dispensados de dar respostas simples e, sobretudo, respostas unívocas. Os exemplos sem dúvida são mais numerosos lá onde o primeiro choque persiste para sempre como um grão de areia que trava o mecanismo; a não ser que tenha cavado um abismo à beira do qual a vida psíquica ameace precipitar-se a cada instante.

Evoco agora o caso de Aurore, não somente porque a dinâmica de sua análise permite interrogar a encenação transferencial dos traumas do início da vida, o a posteriori destes, mas também porque uma sensibilidade particular permitiulhe captar in vivo o nascimento do tempo, dos tempos. Assim, ela podia chegar a uma sessão e ficar admirada daquilo que ouvira a si mesma dizer na sessão anterior: “Eu deveria... Eu nunca pensaria falar daquela maneira”. É evidente que não apenas a forma verbal está sendo posta em questão, ela é indissociável do afeto para o qual se abre - aqui o remorso - que implica ao mesmo tempo a existência do passado e o sonho de sua ressignificação.

A análise de Aurore não pode ser relatada, não mais do que qualquer outra. A posterioris e réplicas se encarregam de embaralhar toda pretensão à cronologia. Entretanto, uma vez que o próprio do a posteriori é, ao menos, abrir a possibilidade da história, acontece que os tempos da análise se constituem em momentos.

Este caso foi dos mais ásperos — sem dúvida, representou um papel de primeira marcha, tanto para o movimento do tratamento quanto para a inscrição no tempo. Uma vez que "o tempo é medido pela afeição" (LYOTARD, 1998, p.53), esse momento durou um longo, longo tempo. Minha inquietação era o único meio de que eu dispunha para medi-lo. Aurore começou a se ausentar, mais do que o habitual. Nunca vinha uma semana completa, nunca a três sessões seguidas. Sempre fazia uma aparição, mínima à maioria das vezes, reduzida a meia sessão, quando não a alguns minutos. Houve uma ocasião em que ela surgiu, com o rosto lívido, a fisionomia desfeita, apenas no exato instante em que a sessão terminava: "Se eu deixar de vir por uma semana, então não virei mais". Uma semana comum de férias (seria mais justo falar em feria, ${ }^{1}$ sem o s) levounos a considerar o nada. “Eu pensei em ir embora...”, relatou então. Ausente, ela

\footnotetext{
${ }^{1}$ Do lat. feria, ae, singular de feriae, arum, 'dias de descanso'. (N. do T., segundo http:// www.aulete.uol.com.br/f\%C3\%A9ria\#ixzz2GjAVt1cK)
} 
ficava sempre sem avisar. "Avisar" é um ato temporal complexo que pressupõe a disponibilidade psíquica de uma antecipação, de um futuro, que não existia aqui. Minha espera trazia a marca, na incapacidade em que eu estava de ocupar, de dispor de um tempo nada menos do que livre. Eu a esperava.

Nos poucos minutos semanais que passava no divã, dizia-me que não podia, não sabia dizer nada do que estava acontecendo. Aurore sonhava, mas eram sonhos como pedaços de obscuridade dos quais não recuperava nada. O mérito de tais sonhos era igualmente essencial, o de manter o fio da análise durante a noite, durante a vida: "Se eu sonho, de que adiantaria não vir?"

Esse momento teve fim após semanas — ou teriam sido meses? Eu não saberia fazer essa conta - , ao mesmo tempo que o primeiro sonho foi novamente lembrado. Uma extensão d'água sem limites e sem ondas, paisagem velada por uma bruma de calor, apenas perturbada pela passagem ao longe de um veleiro antigo. O acontecimento do sonho era mais importante que seu comentário. Ficamos detidos na imagem.

As coisas poderiam ficar deste jeito, se não meaning-free [sem significado], em todo caso sem significação desenvolvida, sem que tivesse sido possível "contar o que tinha acontecido”. Nesse nível de regressão profunda, sem dúvida a coisa não é rara, quando a transferência transporta um pedaço de vida, sem as palavras para dizê-lo. Constata-se a mudança, o rosto não é mais o mesmo. Até a atitude, os ingredientes do estilo, se distribuíram de outra maneira — o estilo é a alma. Não se saberia dizer como nem por quê. Em análise os dois protagonistas apenas falam, vivem; isso não exclui que os deslocamentos que tocam no fundo fiquem sendo histórias sem palavras, se não sem semiologia.

Tudo se seguiu de outro modo, sem que eu pudesse decidir se foi por acaso ou por necessidade. Aurore chegou à sessão muito pálida. Tinha acabado de ficar sabendo da morte de um velho amigo da família, mas isso não era o pior. A morte era esperada, iminente, e ela estava preparada para isso. Na antevéspera, havia telefonado para seus pais, que a tinham tranquilizado: situação estacionária, sem novidades. Porém, a notícia era falsa, o amigo já tinha morrido. Os pais, procuravam, desta maneira, deliberadamente protegê-la por mais um dia, uma vez que sabiam que ela estava na iminência de ter importante encontro profissional. As palavras que Aurore balbuciava não chegariam a captar algo de um impensável, essas vinte e quaro horas sem vida nem morte, esse tempo em branco que ela tinha não vivido, esse momento de não existência. As palavras fracassam quanto a dizer isso que não é simplesmente uma negação, nem mesmo uma mentira, antes uma suspensão acima do vazio, quando se acredita que o chão ainda está debaixo de seus pés.

Por que caminho? O apagamento das representações não permite que sejam relatadas, não mais do que um encadeamento de associações, uma descida de 
escada em que se pulariam alguns degraus; sempre acontece que a sequência precedente, alguns meses depois, volte a ficar evidente. O que tinha sido apenas o tempo sem tempo de um desamparo sem sentido apareceu invertido, tão exato em sua duração — dois meses — quanto em suas datas de início e fim: a primeira, a do nascimento de Aurore; a segunda, aquela que deveria tê-la visto nascer, caso ela não tivesse nascido prematura. O que a imagem do sonho com água permitia pressagiar ficava confirmado: esse tempo "sem" se acabava com um sonho de nascimento.

Um primeiro momento tão traumático quanto sem sentido, uma outra cena, ela também em branco, mas uma cena recordada, que desperta como uma ferroada e permite que o sentido advenha... a temporalidade reconhecível é a do fenômeno a posteriori mesmo se na ocasião tudo se representa em adiamento. Os dois meses à deriva não constituem o primeiro choque, mas sim sua “repetição", sua invenção; mas vinte e quatro horas em branco não constituem o tempo 1, e sim sua representação.

As perguntas são múltiplas, gostaríamos de conservá-las, mas uma vez que são escritas, corremos o risco de respondê-las. Pierre Fédida evocava a "força selvagem" da transferência... Como chegar a pensar que o não vivido desses dois meses que não foram possa chegar a ser vivido, a se (re)produzir, a encarnar seu desaparecimento na "relação de desconhecido" da transferência? Seguramente não foi apenas essa experiência de "não experiência" que se repetiu. Coisas foram ditas, um mito da família se esboçou. Apenas o pai desejava um filho, a mãe não queria; poucos dias se passaram após o nascimento e ela retomava suas atividades profissionais. É sempre um adulto que "faz prematurar" uma criança. Mas o enigma persiste, uma vez que não são as coisas ditas ao sabor de uma talking cure que caracterizam esse tempo de outro planeta. Confrontada aos traumas do início da vida, a psicanálise se vira para a obstetrícia (mais do que para a maiêutica) — essa é uma constatação feita por vários autores (WINNICOTT, 1969/1949). Não pode nascer de verdade quem não é esperado. Isso não basta para "voltar" a isso, nem ao analista para ater-se a isso. Uma vez que a realidade que a transferência atualiza é sempre, sem exceção, a realidade psíquica, visto que esta nunca é o simples decalque de "algo que aconteceu", quando mesmo as deformações seriam rudimentares, a transferência, paradoxalmente, é a repetição daquilo que nunca se passou. Mas aqui é verdade antes duas vezes do que uma só.

O estabelecimento da correspondência da temporalidade teórica do a posteriori com momentos do tratamento, é coisa difícil de fazer, é inevitável que seja apenas uma aproximação. Perguntei-me o que tinha provocado, mas também permitido, essa regressão tão perigosa quanto fecunda. Para tal questionamento eu não tenho a resposta, mas isto não impede a convicção — muito pelo contrário. O mito não é mais familial, torna-se analítico. Nós contamos uma história que 
aspira apenas a se tornar "verdadeira". Algum tempo antes — sempre a mesma incerteza quando se trata de tomar a medida do tempo analítico que passa precisei interromper minha atividade durante uma semana, fora dos períodos comuns de férias. Não deixei de perceber o risco que fazia Aurore correr - o da descontinuidade - e propus-lhe a reposição de duas das três sessões. Restava uma, "anulada", remetida ao nada... De maneira violenta, ela me fez saber que eu não tinha esse direito... Será que a encarnação ulterior da "vida não vivida", os dois meses de desamparo transferencial, seja a elaboração, o engendramento desse acontecimento desafortunado? Podemos adivinhar a hipótese subjacente: tempo 1, aquele que abre o tempo, a sessão suprimida, Aurore anulada, o ódio expressado e depois recalcado; tempo 2, o do primeiro choque, a duração elidida da gestação, a impaciência materna, impossibilidade de esperar, a expulsão precipitada, um golpe no vazio ao amanhecer dos tempos. Em seguida, os dois meses in absentia, e a morte em branco, como tantas réplicas e metamorfoses de uma primeira matéria bruta.

Isso traz de volta a intuição de Winnicott, quando percebeu que na hora transferencial dos traumas do início da vida, as fraquezas, os failures, ${ }^{2}$ as rachaduras do analista se encontravam investidas de uma função dinâmica muito particular. É com mais frequência o analista, com a “ajuda” da contratransferência, quem interpõe a si próprio e ao paciente a vidraça contra a qual este vem brutalmente se chocar. Em região tão profundamente desconhecida, região anterior às palavras, em que o analista se desloca sem bússola, a coisa é quase inevitável. Isso não diminui o paradoxo: ninguém conseguiria transformar em "técnica" o que só é oferecido pela atuação do inconsciente, significado de contratransferência. Ninguém anulará sessões para ver... Entretanto, não é preciso fazer tanto: a deficiência chega, com certeza. Para a criança como para o paciente, o pior risco não é esse, é antes o seu inverso: a ameaça da "perfeição", a ameaça da mãe ou de um analista que estão sempre certos da Verdade. ${ }^{3}$ Fora desse caso particular, a falência acaba acontecendo. Para isso, basta que o analista faça sua tarefa, que interprete, ele tem todas as oportunidades de errar... ou pior, de cair (ferir) com exatidão.

\section{A QUE FORÇASS TAL PSICANÁLISE DEVE SUA DINÂMICA?}

O tratamento de Aurore bem depressa impôs um contraste: o vazio de sua presença, a intensidade de sua ausência. Ela nada diz, ou, em todo caso, faz o possível

\footnotetext{
${ }^{2}$ Fracassos. Em inglês no original (N. do T.).

${ }^{3}$ Winnicott escreveu: "Muitas análises fracassaram no final porque o analista não conseguia admitir uma ilusão de fracasso, em razão de sua necessidade pessoal de comprovar a verdade da teoria psicanalítica pela cura de um paciente" (200/1963, p.87).
} 
para conseguir isso; palavras escolhidas e repetidas, esticadas, esvaziadas. Fica impossível "relatar para mim mesmo" a sessão a posteriori. Ela não tem lembranças da infância, eu não tenho lembrança da sessão. Ela está lá de outro modo quando não vem. Independentemente dos dois meses patéticos já evocados, Aurore fez o máximo emprego daquilo que o "pagamento das sessões a que se faltou” pode permitir. Faltou? Não convém usar aqui este “termo estereotipado”. Seria mais justo dizer "de que esteve ausente". Onde quer que estivesse na hora da sessão, Aurore experienciava um sentimento indefinível, alguma coisa que não é da atualidade. Não há exceção: ela nunca avisa; minha espera depende disso. Mais tarde, quando esses atos virão a ser "elevados à significação”, ela poderá comentar: "se eu avisar, a sessão não vai acontecer”. De ausência em ausência, Aurore explora sua aptidão à sobrevivência, minha aptidão à sua sobrevivência. Talvez seja na intranquilidade do Nebenmensch que se abra a primeira brecha constitutiva do tempo — como a continuidade de seu investimento funda a continuidade de ser do recém-nascido. O primeiro “eu” é um outro, o primeiro tempo também. To be or not to be, conforme se seja ou não esperado. Ele (ela primeiro) me espera, logo, eu sou.

A esse jogo aí, o da psicanálise in absentia — claramente menos divertido do que o jogo do carretel, porém não sem relação — , no entanto, o presente, por ser precioso a esse ponto, termina por se tornar vivo. Diz a verdade a língua, que não tem um termo para dizer "presente" e "presença”. Para o presente, é preciso ser dois, todo presente é inter-humano, interpsíquico. O presente é uma coincidência, do ser e do tempo. Somente a existência psíquica de um "em presença de" dá ao presente sua eventual consistência. As condições de possibilidade psíquica do efeito de a posteriori são constituídas então: o golpe, o trauma, o acontecimento é a vida do presente; o a posteriori acrescenta aí a abertura para o passado.

Nesse dia, já instalada no divã, ela diz: "eu poderia morrer aí de boca aberta, você não ia fazer nada”. O desamparo do tom desta vez nos deixava muito longe do "não dizer nada”. Vários anos de análise depois, voltou a lembrança dessa irrupção e de seu desespero — mas antes não havia "lembrança”, nem mesmo de "antes". E ela se lembra então: certamente não teria suportado que eu "fizesse" alguma coisa. Interpretar, por exemplo. As palavras, no entanto, estavam à disposição. Ao contrário da sequência insondável precedente, o sentido dessa vez estava constituído e a repetição transferencial do trauma primordial podia ser expressada. Aurore tinha apenas poucos meses de nascida quando levou a anorexia até o ponto do risco de vida. Foi a intervenção de um amigo da família que a salvou, já que seus pais estavam derrotados pelas circunstâncias. O que terá sido, então, que permitiu que o analista resistisse à tentação das palavras, daquelas que se apressam a apreender, a compreender... a alimentar, a opor sua competência àquela que faltou outrora? Nada, a não ser a intuição do instante, 
as "pequenas percepções" que o compõem: adivinhar que a palavra visaria primeiro a aliviar a angústia contratransferencial, pressentir a violência que haveria em remeter muito apressadamente a mulher de hoje ao lactente de ontem, entrever que a criação do acontecimento, de seu presente, é mais importante que sua tradução, não fazer um curto-circuito no tempo que separa o golpe de seu a posteriori. Viver antes de contar, ser antes de conjugar: "hoje, aqui como outrora, em outro lugar..."

Antes que a questão das regressões profundas no tratamento mobilizasse a reflexão teórica nos anos 1950, Freud, às voltas com as inovações de Rank e Ferenczi, já tinha destacado a forma alucinatória que, de maneira privilegiada, reveste o retorno transferencial dos acontecimentos esquecidos dos primeiros anos, na ocasião em que a criança dispõe apenas dos primeiros elementos da palavra (FREUD, 2010/1937, p.78-79). A jogada pode ser assim resumida, correndo o risco de forçar o traço: ou o movimento regressivo do tratamento permite retomar esse ponto em que a atuação do inconsciente tem a força que a alucinação lhe dá, ou é a "análise para nada”. O a posteriori dos traumas elementares, sua "elevação à significação", sua ligação ao passado, sua historicização, sua transformação, esse a posteriori não está fora do alcance da experiência analítica: ele tem como condição o “presente absoluto” da alucinação. É impossível sustentar que essa condição é a única suficiente, mas é necessária. Nas palavras de Winnicott: “A prova inicial da primitive agony só pode ser ligada ao passado se o eu pôde primeiramente recolhê-la na experiência temporal de seu próprio presente” (2000/1963, p.210).

“Eu podia explodir aí, você não ia fazer nada”... A tensão, a violência desse momento o situa o mais perto possível de um presente vivo. Entretanto, Aurore não grita "estou morrendo, e você não faz nada". A percepção do condicional, na hora trágica do enunciado, sem dúvida, na melhor das hipóteses, fica subliminar. Isso não impede que o índice temporal já assinale mais o depois do que o próprio golpe. ${ }^{4} \mathrm{O}$ condicional é irmão do imperfeito, de um tempo que marca mais do que qualquer outro a existência do passado, seu movimento, sua vida, sua duração. E a existência do passado pressupõe que o presente, o encontro do ser e do tempo, já teve lugar; que esse encontro, talvez mesmo tendo escapado aos dois protagonistas da situação, já os "possuiu”.

A continuação pertence ao jogo da análise. O condicional refaz a história, mais fortemente a imagina, cria-a, revela a natureza paradoxal da ficção. A fantasia precede a lembrança, e sem dúvida permite-a. O desespero descobre que a fantasia desespera do passado. É sempre este último que se trata de modificar, ou

\footnotetext{
${ }^{4}$ Qual foi o golpe? Nenhuma ideia... meu silêncio por ocasião da sessão anterior, uma palavra intempestiva, outra coisa?
} 
melhor, de inventar. Uma vez que a história é um relato, é possível reescrevê-la. Decerto, é mais surpreendente quando é a própria história, categoria psíquica inexistente até então, que a análise vê nascer. "No início, quando eu vinha aqui...”, a primeira história, a história primeira é então a da transferência. Uma história talvez capaz de rememorar sua pré-história, quando o tempo ainda não estava dentro do tempo. Aurore: "você me disse três sessões, você teria dito uma, ou todos os dias, isso teria sido quase a mesma coisa".

É ao mesmo tempo uma hipótese e uma convicção, a de uma profunda cumplicidade entre o fenômeno do a posteriori e a dinâmica da transferência. O trauma in prosentia, “o acontecimento real”, diz Freud (2005/1915 e PONTALIS, 1990), e o advento do sentido, essa conjunção é característica do efeito de a posteriori e do par transferência/interpretação. É inevitável que uma concepção como essa envolva a ideia de conjunto que se tem da psicanálise, na teoria e na prática, e se sustenta por uma representação implícita do tratamento. O exemplo de Aurore permite esboçar essas linhas. Qual a natureza do trauma que a palavra "prematuração" condensa, já simboliza, e que a transferência atualiza? Não se corre grande risco ao supor que ela reúne quase todos os ingredientes: o vital, a destrutividade, a aspiração ao vazio, o sexual, sob o duplo registro do narcísico e do objetal. Mas fica que no cerne dessa diversidade, é no sexual infantil que o tratamento (inter) psíquico se apoia para operar suas transformações; é dele que pode surgir o poder de metamorfose: ao término desses dois meses de uma cena primitiva que não termina mais, tornar-se uma criança esperada, desejada. Nascer, enfim! Falta ao vital, tanto quanto à destrutividade, aquilo que, ao contrário, caracteriza as pulsões sexuais - pelo menos sob sua face de libido objetal: “a extraordinária plasticidade", uma plasticidade para a qual o efeito transformador do a posteriori é operador essencial. O fato de se levar em conta os traumas do início da vida, a ferida que causam a Narciso, a afronta ao recalcado originário, aos primeiros golpes não tratados, impõem uma reflexão prática a propósito das modalidades da regressão e ao trabalho da transferência. A meu ver, não mudam nada naquilo que constitui a sexualidade infantil da psicanálise. À primeira vista a segunda tópica empurra para longe o sexual infantil, e mais fundamentalmente complexifica seu sentido, desloca-o: era o objeto da investigação, da análise; desde o primeiro contato torna-se o recurso para isso.

No testemunho que dá de sua análise com Winnicott, Margaret Little escreve: “a sexualidade infantil só pode mesmo ficar fora de propósito e sem nenhuma significação enquanto o sujeito não tiver se certificado de sua própria existência, 
de sua sobrevivência, e de sua identidade". ${ }^{5}$ Mas todo seu texto mostra o contrário, e, de início, o próprio gesto desse testemunho, sua transgressão, verdadeira declaração de amor transferencial... não liquidado. Temos o sentimento de que Winnicott foi o homem da sua vida (de Margaret Little). Acrescentam-se aí muitos pormenores, especialmente as trocas recíprocas de situação entre vida sexual e vida analítica; e algumas ingenuidades: a “pequenina Margaret” recebe como sinal da maternagem os bolinhos que seu analista lhe oferece por ocasião dos finais de sessão, como se nossas pequenas madeleines ${ }^{6}$ e os bolinhos deles visassem a alimentar. Se a sexualidade infantil não se misturar nos assuntos de cozinha, então não haverá nunca bolinhos, presentes. Não há um só bolinho que seja inocente. Margaret Little vem ao tratamento com uma questão vital, existencial (o que vem a ser "eu própria”?), mas é o amor de transferência que permite o trabalho de resolução, que traz a ação de transformação. ${ }^{7}$ O raciocínio é o mesmo seguido por Freud a propósito do sonho. Enquanto ele pôde acreditar que o sonho era sempre satisfação de desejo, o sexual infantil constituiu seu único conteúdo verdadeiro. Até o dia, por ocasião da segunda tópica, em que Freud se deu conta de que em determinadas condições traumáticas, o sexual passava para o outro lado: não era mais conteúdo, era o operador, transformador, força de trabalho. O mesmo movimento se aplica ao a posteriori, o que permite a atuação do inconsciente na transferência. Agente do remanejamento psíquico, o efeito de a posteriori se apoia na plasticidade pulsional. Será que ele revela o caráter sexual do primeiro golpe, o primeiro ataque é sempre um sexual pré-sexual, ou será que ele opera a sexualização de um trauma (vital, destrutivo, identitário...) que não era sexual? A abertura da questão é mais interessante do que a resposta que, desconhecida em tal grau, só poderia ser redutora.

Com ou sem bolinho, sem ficar mimando, a psicanálise é uma cena de sedução: aquela que nasce do encontro entre o mais íntimo e o mais estrangeiro e que permite que o fenômeno do a posteriori, descoberto com a teoria da sedução, se veja novamente em seu país natal. O gesto sedutor consiste simplesmente no enunciado da regra fundamental: "diga qualquer coisa que lhe passe na cabeça...". O Homem dos Ratos é o primeiro a ouvi-la, e sabemos qual foi a continuação: a alucinação do suplício dos ratos que o faz levantar-se com precipitação do divã, para fugir do analista cruel. O gênio de Freud — ao instituir a duplicação: livre associação/escuta flutuante — foi ter submetido ao regime polimórfico e

\footnotetext{
${ }^{5}$ Quando Winnicott trabalha nas zonas em que predominam as angústias psicóticas — um relato pessoal, em Transfert et états limites (sob a direção de J. André e C. Thompson. Petite Bibliothèque de Psychanalyse. Paris: PUF, 2002).

${ }^{6}$ Bolinho que se come na hora do chá, tornado célebre por Proust no À la recherche du temps perdu.

${ }^{7}$ A crítica não poupa Winnicott e sua "regressão à dependência", que ele espera poder manter protegida da vida pulsional.
} 
autoerótico da sexualidade infantil tanto a palavra do paciente quanto a escuta do analista. As condições psíquicas desse dispositivo estão longe de estar sempre reunidas, mas a que visa a técnica do jogo de Winnicott, senão a estabelecê-las, talvez mesmo a inventá-las?

A situação analítica repete, em sua forma, como afirmou Jean Laplanche, a dissimetria do infans e do Nebenmensch, a mesma que constitui a matriz dos primeiros golpes. Essa repetição não é um simples decalque. O “comércio” do analista e do analisando reúne dois adultos, a criança anterior ao inconsciente nunca se apresenta em análise. Se a analogia tem fundamento, é através da ideia de que a dissimetria é originária, que carimba para sempre a experiência humana com sua marca e seu enigma, e que seu acontecimento é muitas vezes reproduzido, em especial depois de instaurada a situação analítica.

"O amor é cego..." - pelo fato de ser um "amor verdadeiro", o amor de transferência não deixa de engendrar uma parcela de ilusões, em especial a de um acordo, uma conivência, uma partilha, e mesmo uma aliança (terapêutica)! Talvez mesmo um divórcio por mútuo consentimento: “foi de acordo com meu analista que meu tratamento teve fim". Tantas maneiras de desconhecer a insuportável dissimetria, o mal-entendido fundador. E assim vai a vida da análise... com a condição de que esta não se prive de submeter as ilusões engendradas pelo amor ao seu trabalho de desligamento. Mas o que pensar dessas teorias sexuais, ao mesmo tempo infantis (contratransferenciais) e analíticas, fomentadas de maneira insidiosa pelo movimento do tratamento e que se transformam em teorias psicanalíticas apenas? Falar-se-á de "partilha de afeto" ou de "relação transferencial-contratransferencial”. Por certo estas últimas palavras, tão bárbaras, francamente não são as do amor, não tornam menos simétrico o que não poderia ser. Não há relação analítica se não houver relação sexual. Uma análise nunca vai ter lugar entre pessoas que se entendem. Não há nada mais afastado da ideia da psicanálise do que a de "mutualidade”. Um trauma, mesmo do início da vida, pode dar lugar à metamorfose, por pouco que o acontecimento real e o a posteriori da transferência lhe deem ocasião, mas a dissimetria psíquica que constitui sua fonte e seu pano de fundo não pode, de maneira alguma ser apagada; como também a alteridade do inconsciente não pode ser eliminada.

Recebido em 25/2/2013. Aprovado em 21/3/2013. 


\section{REFERÊNCIĀS}

FREUD, S. (2010/1937) “Constructions dans l'analyse”, in Euvres complètes. Paris: PUF, v.XX, p.70-71.

(2005/1915) "Remarques sur l'amour de transfert", in Euvres complètes. Paris: PUF, v.XII, p.208.

. (2010/1937) "L'analyse finie et l'analyse infinie", in Euvres complètes. Paris: PUF, v.XX, p.28.

LYOTARD, J-F. (1998) La confession d'Augustin. Paris: Galilée.

PONTALIS, J.-B. (1990) "L'étrangeté du transfert", in La force d'attraction. Paris: Seuil.

WINNICOTT, W.R.D. (1969/1949) “Les souvenirs de la naîssance, Le traumatisme de la naîssance et l'angoisse”, in: De la pédiatrie à la psychanalyse. Paris: Payot.

(2000/1963) "La crainte de l'effondrement", in La crainte de l'effondrement et autres situations cliniques. Paris: Gallimard. 